\title{
Corrigendum: Two-Stage Stochastic Scheduling of Integrated Electricity and Natural Gas Systems Considering Ramping Costs with P2G Storage and Wind Power
}

\author{
Xiaozhe Song ${ }^{1}$, Chuqiao Lin $^{2}$, Rufeng Zhang ${ }^{2}$, Tao Jiang ${ }^{2 *}$ and Houhe Chen ${ }^{2}$ \\ ${ }^{1}$ State Grid Jilin Electric Power Company Limited, Changchun, China, ${ }^{2}$ Department of Electrical Engineering, Northeast Electric \\ Power University, Jilin, China
}

Keywords: power-to-gas, ramping cost, wind power accommodation, stochastic programming, natural gas system

\section{OPEN ACCESS}

Approved by:

Frontiers Editorial Office, Frontiers Media SA, Switzerland

${ }^{*}$ Correspondence: Tao Jiang

tjiang@neepu.edu.cn

Specialty section: This article was submitted to

Smart Grids,

a section of the journal Frontiers in Energy Research

Received: 06 February 2021 Accepted: 19 February 2021

Published: 30 March 2021

Citation:

Song $X$, Lin C, Zhang $R$, Jiang $T$ and Chen $H$ (2021) Corrigendum: Two-

Stage Stochastic Scheduling of Integrated Electricity and Natural Gas Systems Considering Ramping Costs with P2G Storage and Wind Power. Front. Energy Res. 9:664782. doi: 10.3389/fenrg.2021.664782

\section{A Corrigendum on}

Two-Stage Stochastic Scheduling of Integrated Electricity and Natural Gas Systems Considering Ramping Costs With Power-to-Gas Storage and Wind Power

by Song, X., Lin, C., Zhang, R., Jiang, T., and Chen, H.. Front. Energy Res. 8:596774. doi:10.3389/fenrg. 2020.596774

There is an error in the Funding statement. The correct Name for the Funder is "science and technology project of State Grid Jilin Corporation (SGJL0000DKJS2000287).”

\section{FUNDING}

This paper was supported in part by science and technology project of State Grid Jilin Corporation (SGJL0000DKJS2000287). The authors declare that this study received funding from science and technology project of State Grid Jilin Corporation. The funder had the following involvement with the study data collection.

The authors apologize for this error and state that this does not change the scientific conclusions of the article in any way. The original article has been updated.

Copyright (-) 2021 Song, Lin, Zhang, Jiang and Chen. This is an open-access article distributed under the terms of the Creative Commons Attribution License (CC BY). The use, distribution or reproduction in other forums is permitted, provided the original author(s) and the copyright owner(s) are credited and that the original publication in this journal is cited, in accordance with accepted academic practice. No use, distribution or reproduction is permitted which does not comply with these terms. 